\title{
DETERMINACION DE LOS REQUERIMIENTOS DE PROTEINA Y ENERGIA DE JUVENILES DE PACO, Piaractus brachypomus ( PISCES CHARACIDAE)
}

\author{
W alter G utiérrez* \\ J avier Zaldívar* \\ Sonia Deza** \\ M ariano R ebaza**
}

\section{RESUMEN}

Fueron formuladas seis dietas experimentales que contenían dos niveles de proteína bruta $(27,4 \%$ y $29,8 \%$ ) y tres niveles de energía digestible(2700, 2900 y $3100 \mathrm{kcal} / \mathrm{Kg}$. de alimento) por cada nivel de proteína para determinar los requerimientos de proteínas y energía y la relación optima energía/proteínas para alevinos de paco en condiciones controladas. Las dietas fueron formuladas para contener dos niveles de metionina + cistina $(0,95 \%$ para $27,4 \%$ de proteína y $1,03 \%$ para $29,8 \%$ de proteína). Se utilizaron los siguientes ingredientes: harina de pescado torta de soya, maíz amarillo duro y polvillo de arroz, además de aditivos como premezcla de vitaminas y minerales, bentonita (ligante) y BHT (Antioxidante). El aceite de pescado sirvió para ajustar los niveles de energía requeridos.

Las dietas experimentales fueron suministradas en triplicado a grupos de cuatro peces juveniles con pesos promedios de 179, $45+-8,39 \mathrm{~g}$., colocados en 18 estanques de fibra de vidrio de 300 litros de capacidad efectiva cada uno, alimentados con un flujo de agua proveniente del subsuelo con una temperatura de $26,08+-0,75$ grados centígrados, oxígeno disuelto de 5,34 +- 0,82 mg/l y $\mathrm{pH}$ de 5,88 + - 0,16. Las dietas fueron suministradas ad líbitum dos veces por día, reajustadas cada dos semanas, durante noventa días. Con respecto a la ganancia de peso y retención de proteína corporal se encontraron diferencias. significativas $(P<0.05)$ entre tratamientos. El análisis estadístico demostró que niveles mínimos de $29,8 \%$ de proteína bruta y 2700 kcal de energía

\footnotetext{
* Investigadores del instituto veterinario de Investigación tropicales y de alturas ( IVITA) de la U niversidad Nacional M ayor de San M arcos.

** Investigadores del CRI - IIAP - U cayali
} 
digestible/Kg. de alimento son los requeridos por juveniles de paco en dietas de crecimiento para obtener una adecuada ganancia de peso y una eficiente retención de proteínas, con una relación energía digestibles/proteínas de $9,0 \mathrm{Kcal} / \mathrm{g}$ de proteínas.

Palabras clave: Proteína, energía, nutrición, Paco, Piaractus, Pisces.

\section{ABSTRACT}

Six diets were formulated to determine the minimum requirement of protein and digestible energy and the optimum digestible energy: protein ratio(DE/P) for paco Piaractus brachypomus. Two crude protein levels $(27,4 \%$ and $29,8 \%)$ and three digestible energy levels $(2700,2900$ and $3100 \mathrm{kcal} / \mathrm{kg})$ at each protein level were utilized. The diets were formulated to contain two levels of methionine plus cystine( $0,95 \%$ for $27,4 \%$ protein and $1,03 \%$ for $29,8 \%$ of protein). Fish meal, soybean meal, corn yellow grain and rice polishings, moreover vitamins and minerals premix, bentonite and $\mathrm{BHT}$ (antioxidant) were used to elaborate the diets. The fish oil was used for adjust the energy levels required. The experimental diets were fed in triplicate to juvenile fish weighing $179,45+-8,39$ $\mathrm{g}$ and kept in circular fiber glass tanks of 300 liter of capacity. The temperature of water, dissolved oxygen and $\mathrm{pH}$ were $26,08+-0,75 \mathrm{C} ; 5,34+-0,82 \mathrm{mg} / \mathrm{l}$ and $5,88+-0,16$ respectively. The diets were fed ad libitum divided into two equal feedings and adjusted weekly for 13 weeks. Based on average daily gain the diet containing $29,8 \%$ crude protein, $2700 \mathrm{kcal} / \mathrm{kg}$ and an optimum DE/P ratio of $9,0 \mathrm{kcal} / \mathrm{g}$ protein diet appeared to be utilized more efficiently in terms of gain body weight and porcent protein retained.

\section{INTRODUCCION}

El cultivo de peces, como una de las formas menos tradicionales, requiere el entendimiento adecuado de la reproducción, manejo, control de enfermedades, genética, alimentación, nutrición y mercado. Cada una de estas áreas están íntimamente ligadas y solo el manejo apropiado de todos los aspectos de la operación permitirá el cultivo y comercialización exitosa de cualquier especies piscícola. 
La nutrición de peces cultivables es relativamente nueva y primitiva en términos de conocimientos acumulados y niveles de sofisticación cuando es comparada a la nutrición de aves y vacunos. Actualmente los estudios nutricionales en peces se concentran en la evaluación de la proteína y la energía de la dieta, en relación a funciones de crecimiento, reproducción y mantenimiento, con la finalidad de mejorar la producción económica de estas especies. Factores como el patrón de aminoácidos de la proteína, nivel de consumo de proteína, contenido de energía y estado fisiológico del animal han sido discutidos en el contexto de la nutrición de peces por Cowey y Sargent (1972), M ertz (1972) y Cowey (1978).

El nivel mínimo de proteína de la dieta que proporciona una ganancia de peso óptimo fue estudiado por primera vez con el salmón "chinook" Oncorhynchus tshawytscha, por De Long et al.(1958). Ese tipo de experimento, desde entonces fue repetido para muchas especies de peces, identificándose niveles ideales de proteína que se sitúan en un amplio rango de $20 \%$ a $60 \%$. A nivel de Latinoamérica, de acuerdo con Castagnolli (1979), son pocos los trabajos realizados con este objetivo.

El paco Piaractus brachypomus, es una especie amazónica, de hábitos omnívoros, tendiendo a frugívora, ya que consume preferentemente frutos y semillas.

Los estudios de nutrición con especies amazónicas son muy escasos y dispersos, la mayoría de ellos realizados en estanques de tierra. Eyzaguirre y Cordova (1973), hicieron los primeros estudios con el paco. Eckmann (1983a) condujo estudios de alimentación con esta especie, al canzando un crecimiento de $296 \mathrm{~g}$ en 139 días. Lovshin et al.(1974), en estudios preliminares en estanques de tierra fertilizados con estiércol de ganado, obtuvo para el paco pesos promedios de 992 $\mathrm{g}$, en 360 días de cultivo, utilizando una dieta con $29 \%$ de proteína y una densidad de carga de 2632 peces/ha. Cuando se incrementó la densidad de carga a 4400 peces/ha y se incrementó el nivel de proteína de la dieta a 35\%, el rendimiento fue de $4605 \mathrm{~kg} / \mathrm{ha}$. Da Silva et al. (1978), encontró mejores rendimientos para esta especie a una densidad de carga de 5000 peces/ha. Ferrari y Bernardino (1986), realizaron un experimento en estanques de tierra con pacu, Colossoma mitrei, utilizando una dieta peletizada con $22 \%$ de proteína, alcanzando un rendimiento de $5866 \mathrm{~kg} / \mathrm{ha}$ y una conversión alimenticia de 2.47 . Cantelmo y De Souza(1986), evaluaron el efecto de cuatro niveles de proteína(20\%, $25 \%, 30 \%$ y $35 \%)$ sobre el pacu, no encontrando diferencias significativas entre ellos a un peso promedio de $40 \mathrm{~g}$. Carneiro(1983) encontró que una dieta con 30\% de proteína bruta y $2900 \mathrm{kcal}$ de ED permitía un mejor rendimiento en el pacu. 
Los objetivos de este estudio fueron determinar los requerimientos de proteína y energía y la relación óptima energía/proteína para alevinos de paco mantenidos bajo condiciones controladas. Estos resultados permitirán posteriores investigaciones dentro de los requerimientos nutricionales de esta especie que conducirán a reducir los costos de alimentación.

\section{MATERIALES Y METODOS}

El estudio se realizó en el Centro Regional de Investigación de U cayali del Instituto de Investigaciones de la A mazonía Peruana y tuvo una duración de 90 días. Se emplearon 18 tanques circulares de fibra de vidrio de 300 litros de capacidad efectiva cada uno. La batería de tanques fue abastecida con un flujo continuo de agua proveniente del subsuelo. Los valores de temperatura del agua $(26,08+-0,75$ Grados Centígrados), oxígeno disuelto(5,34 + - 0,82 mg/l) y $\mathrm{pH}(5,88+-0,16)$, se mantuvieron constantes durante todo el experimento.

Se seleccionaron peces saludables y con pesos promedios de 179,45 +-8,39 g. Para la elaboración de las dietas experimentales se utilizaron insumos y subproductos comúnmente disponibles en la región como harina de pescado, maíz amarillo duro, polvillo de arroz y aceite de pescado y aditivos como premezcla de vitaminas y minerales, bentonita y antioxidantes. Las seis dietas experimentales (Tabla 1), se formularon por programación lineal, utilizando el programa L p88. Las dietas contenían 2 niveles de proteína $(27,4 \%$ y $29,8 \%$ ) y tres niveles de energía digestible $(2700,2900$ y $3100 \mathrm{kcal} / \mathrm{kg}$ de alimento) por cada nivel de proteína. Las dietas con $27,4 \%$ tuvieron $0,95 \%$ de metionina + cistina como porcentaje de la dieta y las dietas con $29,8 \%$ tuvieron $1,03 \%$ de metionina + cistina como porcentaje de la dieta. Como fuentes de proteína se utilizaron harina de pescado y torta de soya y como fuentes de energía maíz amarillo duro y polvillo de arroz. Además se usó aceite de pescado que sirvió para ajustar los niveles de energía requeridos. Como aditivos se utilizaron premezcla de vitaminas y minerales, bentonita (ligante) y BHT (antioxidante). La energía digestible fue calculada en base a los valores calóricos de Wilson (1977).

Previo al inicio del experimento, los peces fueron acostumbrados al alimento peletizado durante 15 días. A ntes del experimento y después de cada muestreo los peces fueron sometidos a un baño profiláctico con una solución de violeta de genciana y oxytetraciclina ( $5 \mathrm{ml} / 250$ litros) por 6 horas. 
A cada tanque se le asignó una dieta al azar y por triplicado. Se colocaron 4 peces por tanque. La alimentación fue ad libitum con una frecuencia de dos veces por día. L os muestreos fueron realizados cada 15 días y se evaluaron ganancia de peso, ingesta de alimento, ingesta de proteína, conversión alimenticia, composición corporal (proteína, lípidos, cenizas y humedad) y proteína retenida. Los datos de composición corporal fueron determinados al inicio y al final del experimento sobre la base de una muestra total por cada tratamiento y se expresó en porcentaje de materia seca (AOAC, 1970).

Para evaluar los efectos de las seis dietas se usó el diseño completamente al azar con un arreglo factorial $2 \times 3$ con tres repeticiones por tratamiento. El análisis de variancia y la prueba de Tukey se utilizaron para comparar los efectos de los tratamientos. 
TABLA 1. Composición porcentual, análisis proximal y contenido de nutrientes de las dietas experimentales para juveniles de Paco (Piaractus brachypomus)

FORMULACION

DIETAS EXPERIMENTALES

1

2

3

4

$5 \quad 6$

M aíz

P. arroz

29,98

29,89

$29,99 \quad 29,81$

29,98

29,99

24,92

19,65

14,06

16,61

10,41

04,98

H. Pescado

20,85

20,82

20,80

20,44

20,41

20,39

T. Soya

16,81

18,48

20,22

25,51

27,26

28,97

A ceite

3,92

7,63

11,40

4,61

8,40

12,14

Premezcla V it. + $M$ in.

0,50

0,50

0,50

0,50

0,50

0,50

Bentonita

3,00

3,00

3,00

3,00

3,00

3,00

BHT

0,015

0,015

0,015

0,015

0,015

0,015

\section{ANALISIS PROXIMAL}

$\begin{array}{lrrrrrr}\text { Proteína } & 27,43 & 27,41 & 27,39 & 29,82 & 29,86 & 29,89 \\ \text { Grasa } & 10,63 & 13,13 & 15,68 & 10,01 & 12,48 & 15,02 \\ \text { Humedad } & 11,96 & 11,35 & 10,70 & 10,88 & 10,98 & 10,35 \\ \text { Ceniza } & 6,95 & 6,54 & 5,11 & 5,37 & 6,08 & 5,66 \\ \text { Fibra } & 4,82 & 4,48 & 4,10 & 4,77 & 4,36 & 4,00 \\ \text { Nifex } & 38,21 & 37,09 & 37,02 & 39,15 & 36,24 & 35,00\end{array}$

CONTENIDO DE NUTRIENTES

$\begin{array}{lrrrrrr}\text { Proteína } & 27.43 & 27.41 & 27.39 & 29.82 & 29.86 & 29.89 \\ \text { ED (kcal/g). } & 2.70 & 2.90 & 3.10 & 2.70 & 2.90 & 3.10 \\ \text { ED/P (kcal/g de proteína). } & 9.80 & 10.58 & 11.32 & 9.05 & 9.71 & 10.37 \\ \text { Lisina (\% de la dieta) } & 1.75 & 1.76 & 1.78 & 1.93 & 1.94 & 1.96 \\ \text { M etionina (\% de la dieta). } & 0.62 & 0.62 & 0.62 & 0.65 & 0.65 & 0.65 \\ \text { M etionina + Cistina } & & & & & & \\ \text { (\% de la dieta). } & 0.94 & 0.95 & 0.96 & 1.02 & 1.03 & 1.04 \\ \text { Calcio. } & 0.90 & 0.90 & 0.90 & 0.90 & 0.90 & 0.90 \\ \text { Fósforo disponible. } & 0.90 & 0.85 & 0.77 & 0.80 & 0.72 & 0.60\end{array}$




\section{RESULTADOS Y DISCUSION}

Al analizar estadísticamente los parámetros evaluados se encontraron diferencias significativas $(P<0,05)$ entre tratamientos con respecto a la ganancia de peso y la proteína retenida (Tabla 2).

Al analizar los efectos de los niveles de proteína sobre la ganancia de peso, dentro de cada nivel de energía digestible (Tabla 3), los dos niveles de proteína presentaron efectos significativamente diferentes $(P<0,05)$ en el tratamiento que contenía $2900 \mathrm{kcal}$ de energía digestible por kilogramo de alimento, no encontrándose diferencias significativas cuando los niveles de energía digestible fueron de 2700 y $3100 \mathrm{kcal} / \mathrm{kg}$ de alimento. La aplicación de la Prueba de Tukey demostró que las ganancias de peso dentro de los tratamientos con $27,4 \%$ de proteína y $29,8 \%$ de proteína $(5,33 \%$ y $10,22 \%$ ) difieren significativamente, dentro del nivel de energía digestible de $2900 \mathrm{kcal} / \mathrm{kg}$. Esto significa que para el nivel de energía digestible evaluado, el nivel de proteína de la dieta influyó sobre la ganancia de peso, que fue mayor con $29,8 \%$ de proteína dietaria. En cambio el nivel de proteína dietaria no influyó sobre la ganancia de peso cuando los niveles de energía digestible fueron de 2700 y $3100 \mathrm{kcal} / \mathrm{kg}$ respectivamente.

En el análisis de los efectos de los niveles de energía digestible sobre la ganancia de peso, dentro de cada nivel de proteína, la prueba de Tukey demostró que para el nivel constante de $27,4 \%$ de proteína dietaria, la ganancia de peso del tratamiento con $2900 \mathrm{kcal} / \mathrm{kg}(5,33 \%)$ difiere significativamente $(\mathrm{P}<0,05)$ de las ganancias de peso obtenidas con los tratamientos que contenían $2700 \mathrm{kcal} / \mathrm{kg}$ $(12,53 \%)$ y $3100 \mathrm{kcal} / \mathrm{kg}(11,23 \%)$ lo que implica que para este nivel de proteína, el nivel de energía digestible de $2900 \mathrm{kcal} / \mathrm{kg}$ influyó negativamente sobre la ganancia de peso. Para el nivel constante de $29,8 \%$ de proteína dietaria, las ganancias de peso $(14,86 \%, 10,22 \%$ y $11,48 \%)$ obtenidas con los tres niveles de energía digestible estudiados no fueron significativamente diferentes. N utricionalmente, para el nivel de proteína dietaria analizado $(29,8 \%)$ los niveles de energía digestible, no influyeron sobre la ganancia de peso, siendo la mejor dieta, en términos de ganancia de peso, la que contenía 29,8 \% de proteína y $2700 \mathrm{kcal} / \mathrm{kg}$ de alimento de energía digestible.

En la tabla 4 se presentan los valores medios de proteína retenida, que relacionan la cantidad de proteína fijada por los peces y la ingesta de la misma, demostrando la eficiencia de utilización de la proteína por el paco. El análisis de variancia mostró que los niveles de proteína y energía digestible determinaron efectos diferentes $(P<0,05)$ sobre la retención de proteína. 
TABLA 2. Parámetros zootécnicos obtenidos al final del experimento con diferentes niveles proteicos y energéticos en la alimentación de juveniles de Paco Piaractus brachypomus

PARAMETRO

DIETAS EXPERIMENTALES

$\begin{array}{lllll}1 & 2 & 3 & 4 & 5\end{array}$

6

\begin{tabular}{|c|c|c|c|c|c|c|}
\hline $\begin{array}{l}\text { Peso inicial } \\
\text { (g/pez) }\end{array}$ & $\begin{array}{r}184,5 a \\
+-2,2\end{array}$ & $\begin{array}{l}175,6 a \\
+-7,8\end{array}$ & $\begin{array}{r}177,6 a \\
+-6,5\end{array}$ & $\begin{array}{r}175,4 a \\
+-7,9\end{array}$ & $\begin{array}{r}182,9 a \\
+-8,5\end{array}$ & $\begin{array}{r}179,8 a \\
+-9,3\end{array}$ \\
\hline $\begin{array}{l}\text { Ganancia de peso } \\
(\%)\end{array}$ & $\begin{array}{l}12,5 a \\
+-0,9\end{array}$ & $\begin{array}{r}5,3 \mathrm{ac} \\
+-2,5\end{array}$ & $\begin{array}{l}11,2 a \\
+-3,4\end{array}$ & $\begin{array}{l}14,9 a \\
+-3,5\end{array}$ & $\begin{array}{r}10,2 \mathrm{ac} \\
+-1,0\end{array}$ & $\begin{array}{l}11,9 a \\
+-3,9\end{array}$ \\
\hline $\begin{array}{l}\text { Conversión } \\
\text { alimenticia }\end{array}$ & $\begin{array}{r}3,8 a \\
+-2,6\end{array}$ & $\begin{array}{r}6,9 a \\
+-3,6\end{array}$ & $\begin{array}{r}3,1 a \\
+-1,1\end{array}$ & $\begin{array}{r}2,4 a \\
+-0,8\end{array}$ & $\begin{array}{r}4,0 a \\
+-1,3\end{array}$ & $\begin{array}{r}3,1 a \\
+-0,9\end{array}$ \\
\hline $\begin{array}{l}\text { Proteína } \\
\text { Retenida (\%) }\end{array}$ & $\begin{array}{l}40,9 a \\
+-2,7\end{array}$ & $\begin{array}{r}34,5 b a \\
+-8,6\end{array}$ & $\begin{array}{r}41,7 a \\
+-10\end{array}$ & $\begin{array}{l}45,1 a \\
+-1,6\end{array}$ & $\begin{array}{l}22,4 b \\
+-2,7\end{array}$ & \\
\hline
\end{tabular}

* Los valores promedios seguidos de una misma letra no son significativamente diferentes $(P<0,05)$ por la Prueba de Tukey.

TABLA 3. Ganancias de peso promedio(\%) en el Paco (Piaractus brachypomus)

\begin{tabular}{cccc} 
PROTEINA (\%) & ENERGIA & DIGESTIBLE & (kcal/kg de alimento) \\
\hline & $\mathbf{2 7 0 0}$ & $\mathbf{2 9 0 0}$ & $\mathbf{3 1 0 0}$ \\
$\mathbf{2 7 . 4}$ & $12,5 \mathrm{a} / \mathrm{A}$ & $5,3 \mathrm{~b} / \mathrm{B}$ & $11,3 \mathrm{a} / \mathrm{A}$ \\
$\mathbf{2 9 . 8}$ & $14,9 \mathrm{a} / \mathrm{A}$ & $10,2 \mathrm{a} / \mathrm{A}$ & $14,8 \mathrm{a} / \mathrm{A}$
\end{tabular}

Para cada nivel de proteína, los valores promedios seguidos de igual letra minúscula, no difieren significativamente $(P<0.05)$ por la Prueba de Tukey.

* Para cada nivel de energía digestible, los valores promedios seguidos de igual letra mayúscula, no difieren significativamente $(P<0.05)$ por la Prueba de Tukey. 
Como hubo interacción entre los niveles de proteína y energía, los efectos de los niveles de energía digestible sobre la proteína retenida fueron analizados dentro de cada nivel de proteína dietaria.

En las dietas con $27,4 \%$ de proteína, los niveles de energía digestible no tuvieron ninguna influencia sobre la proteína retenida. Sin embargo en las dietas que contenían $29,8 \%$ de proteína los niveles de energía digestible influyeron significativamente $(P<0,05)$ sobre la proteína retenida.

La prueba de Tukey reveló que los porcentajes de proteína retenida fueron significativamente diferentes $(P<0,05)$ para los niveles de $2700 \mathrm{kcal} / \mathrm{kg}(45,1$ $\%), 2900 \mathrm{kcal} / \mathrm{kg}(22,4 \%)$ y $3100 \mathrm{kcal} / \mathrm{kg}(9,0 \%)$. Existe una disminución de la eficiencia de retención de la proteína conforme se elevan los niveles de energía digestible. Niveles de energía más al tos disminuyen la ingesta de alimento, que se expresa en una menor retención de proteína (Cowey, 1978). Bajo las condiciones estudiadas, los resultados del experimento demuestran que niveles mínimos de $29,8 \%$ de proteína bruta y $2700 \mathrm{kcal}$ de energía digestible/kg de alimento son los requeridos por el paco en dietas de crecimiento para una adecuada ganancia de peso y una eficiente retención de proteína, con una relación energía digestible/proteína bruta de $9,0 \mathrm{kcal} / \mathrm{g}$ de proteína.

\section{TABLA 4. Valores promedios de proteína retenida (\%) en el Paco (Piaractus brachypomus)}

\section{PROTEINA (\%) ENERGIA DIGESTIBLE (kcal/kg de alimento)}

$2700 \quad 3100$

$\begin{array}{rrrr}\mathbf{2 7 , 4} & 40,9 \mathrm{a} / \mathrm{A} & 34,5 \mathrm{a} / \mathrm{A} & 41,7 \mathrm{a} / \mathrm{A} \\ \mathbf{2 9 , 8} & 45,1 \mathrm{a} / \mathrm{A} & 22,4 \mathrm{~b} / \mathrm{B} & 9,0 \mathrm{c} / \mathrm{B}\end{array}$

* Para cada nivel de proteína, los valores promedios seguidos de igual letra minúscula, no difieren significativamente $(P<0,5)$ por la Prueba de Tukey.

* Para cada nivel de energía digestible, los valores promedios seguidos de igual letra mayúscula, no difieren significativamente $(P<0,05)$ por la Prueba de Tukey. 


\section{BIBLIOGRAFIA.}

ASSOCIATION OF OFFICIAL ANALYTICAL CHEMISTS. 1970. Official Methods of A nalysis. Washington, D. C. 400 pp.

CANTELMO, O. A. y DE SOUSA, J. A. 0 1986. Alimentacao do pacú Colossoma mitrei, em diferentes proporcoes de proteína animal e vegetal. Síntese dos trabalhos realizados com especies do genero Colossoma, Centro de Pesquisa e Treinamento em Aquicultura (CEPTA), Pirassununga, S.P. Brasil. 3 pp.

CARNEIRO, D. J. 1983. Níveis de proteína e energia na alimentacao do pacú Colossoma mitrei, Berg 1985. Disertacao de M estrado. Jaboticabal, FCAV-UNESP, 56 pp.

CASTAGNOLLI, N. 1979. Fundamentos de nutricao de peixes. Piracicaba: Livroceres L tda., 108 pp. ilust.

COWEY, C. B. \& SARGENT, J. R. 1972. Fish nutrition. En: Adv. Mar. Biol., 10: 383-492.

COWEY, C. B. 1978. Protein and amino acid requirements of fishes. Proc. Hamburg ,EIFA C/78/Simposium. Hamburg, 18-21/04/1978): R/6. 20 pp.

DA SILVA, A. B.; CARNEIRO, A; MELO, F. R. \& LOVSHIN, L.L. 1978. $M$ ono e policultivo intensivo do tambaqui, Colossoma macropomum (Cuvier) e da pirapitinga, Colossoma bidens (Spix) com o hibrido macho das tilapias Sarotherodon niloticus fémea e Sarotherodon hornorum macho. M éxico D.F.: II Simposio de la Asociación Latinoamericana de A cuicultura.

DE LONG, D. C.; HALVER, J. E. \& MERTZ, E. T. 1958. Nutrition of salmonoid fishes: VI Protein requirement of chinook salmon at two water temperatures. $10 \mathrm{pp}$.

ECKMANN, R. 1983a. Beitrage zu Ernahrung, Wachstum und Fortpflanzung Amazonfischer Characiden in Teichen sowie zur Entwicklung angepasster teichwirtschaftlicher Verfahren im Peruanischen amazonasgebiet. Freiburg: U niv. Freiburg. Ph. D. Thesis 208 pp. 
EYZAGUIRRE, H. F. y CORDOVA, R. V. 1973. A spectos básicos de la producción piscícola en carácidos tropicales. Simp. Int. sobre Fauna Silvestre e Pesca Fluvial y Lacustre A mazónica. Manaos (Brasil): IBDF, SUDEPE. P. A1-A11.

FERRARI, V. A. y BERNARDINO, G. 1986. Efeitos da alimentacao na producao do pacu, Colossoma mitrei em viveiros. Sintese dos trabalhos realizados com especies do genero Colossoma. Pirassununga, S.P. (Brasil): Centro de Pesquisa e Treinamento em A quicultura(CEPTA ). 2 pp.

LOVSHIN, L. L.; DA SILVA, A. B.; FERNANDES, J. A. y SOBRINHO, A. C. 1974. Preliminary pond culture test of pirapitinga, Colossoma bidens (Agssiz) and tambaqui, Colossoma macropomum (Cuvier) from the A mazon river basin. CARPA S/6/74/SE 24.

MERTZ, E. T. 1972. The protein and amino acid needs. In: Halver, J. E. Fish Nutrition. N ew Y ork: A cademic Press pp. 106-143.

NATIONAL RESEARCH COUNCIL. 1973. Nutrient requirements of trout, salmon and catfish. W ashington: National A cademy of Sciences. 18 pp.

WILSON, R.P. 1977. Energy relationships in catfish diets. In: Nutrition and Feeding of Channel Catfish. Southern Cooperative Series. Bulletin 218:2125. 